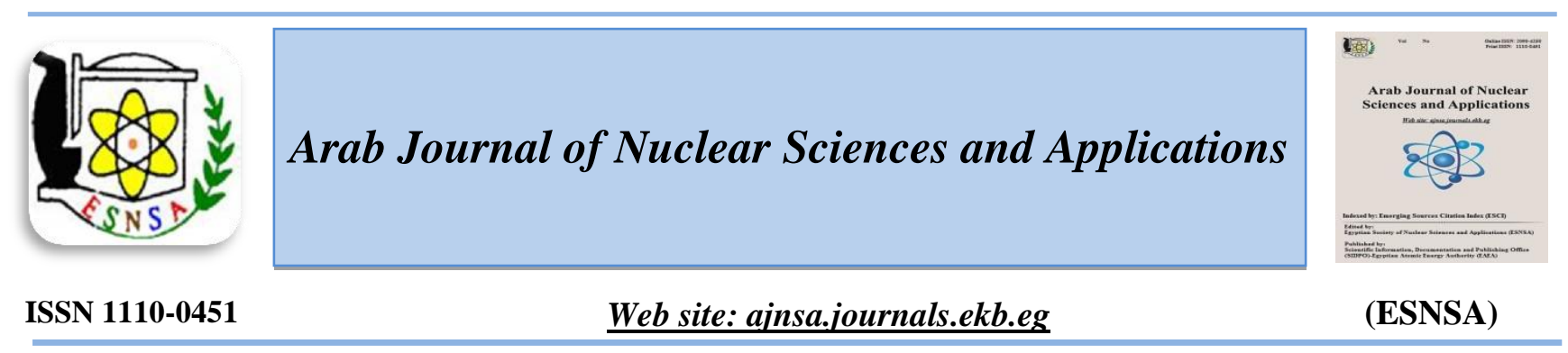

\title{
Mechanical and Gamma Ray Attenuation Properties of N316L Steel Treated by RF Plasma as a Nuclear Material
}

\author{
M. M. Eissa ${ }^{1}$, F. M. El-Hossary ${ }^{2}$, S. U. El-Kameesy ${ }^{3}$, Aly Saeed ${ }^{4 *}$, Al-Zahraa A. Abd Elmoula ${ }^{5}$, Samah A. Al- \\ Shelkamy ${ }^{5}$ \\ ${ }^{I}$ Steel Technology Department, Central Metallurgical Research and Development Institute (CMRDI), Helwan, Egypt \\ ${ }^{2}$ Physics Department, Faculty of Science, Sohag University, Sohag, Egypt \\ ${ }^{3}$ Physics Department, Faculty of Science, Ain-Shams University, Cairo, Egypt \\ ${ }^{4}$ Nuclear Power Stations Department, Faculty of Engineering, Egyptian-Russian University, Cairo, Egypt \\ ${ }^{5}$ Physics Department, Faculty of Science, Assiut University, New Valley, Egypt
}

\begin{abstract}
The effects of plasma surface engineering on average surface roughness, wettability and gamma ray attenuation properties of AISI316L standard steel sample were investigated. The results showed an increase in surface roughness accompanied with an increase in the surface energy and a decrease in the contact angle of the N316L sample treated by plasma carbonitriding. The experimental measurements of gamma ray attenuation properties of the investigated stainless-steel alloys were carried out using gamma lines emitted from ${ }^{232} \mathrm{Th}$ and ${ }^{60} \mathrm{Co}$ gamma ray sources. The attenuation parameters such as linear and mass attenuation coefficients and half value layer were determined experimentally and theoretically. The obtained results indicate that the rf plasma surface treatment is an effective method for developing the surface tribological properties of the treated stainless-steel alloy without any change in the gamma ray attenuation properties. The obtained results suggest the suitability of $\mathrm{N} 316 \mathrm{~L}$ for in-core applications of nuclear reactor systems.
\end{abstract}

Keywords: RF plasma, AISI316L, Roughness, Wettability, Gamma ray, Reactor materials

\section{Introduction}

The in-core of (LWR) and pressure vessels are mainly constructed from austenitic stainless steels (ASS) because of their relatively good mechanical properties [1]. However, ASS position in the core leads to a prolonged exposure of gamma and neutron rays.

Also, progress of nuclear reactors technology always needs to enhance steels which can stand with such conditions [2]. These conditions affect texture of nuclear reactors constructing materials. As a result, there has become an increasing demand for new steels with good tribological properties. Plasma surface engineering steels using carbonitriding method is an old known process for enhancement of texture properties of steels such as wettability and steel surface roughness [3-6]. The topic of surface energy measurements has received a tremendous interest when speaking about wetting or adhesion properties of steels. Wettability and surface energy of steel are affected by both chemical and topographical properties of the native steel.

Wenzel 1936 [7] stated that there is a strong relationship between surface roughness, contact angle and wettability of the surface. Additionally,

Corresponding author: aly 8h@yahoo.com

DOI: 10.21608/ajnsa.2019.2936.1059

(C) Scientific Information, Documentation and Publishing Office (SIDPO)-EAEA 
contact angle is an essential parameter for the detection of mass and heat transfer of stainless steels especially those steels that are used as structural materials for nuclear power plants [8]. Therefore, contact angle is considered a characteristic property for a given solid-liquid system in a special environment. Moreover, it can be considered an indicator of substrate quality [9].

The present work is a further study focused on measurements of average surface roughness, contact angle and surface energy of AISI316L before and after plasma surface engineering method. Additionally, the effect of surface plasma treatment using carbonitriding method on gamma ray attenuation properties of the investigated alloys has been performed and discussed.

\section{Sample preparation}

A standard steel sample AISI316L of chemical composition shown in Table (1) was prepared in CMRDI [10] using ESR method for nuclear applications. Before the plasma surface engineering, the sample was cut to achieve dimension of $2.5 \mathrm{~mm} \times 2.5 \mathrm{~mm} \times 9 \mathrm{~mm}$ polished and cleaned in an alcohol bath for 15 minutes using an ultrasonic device. The plasma surface modification was applied for one hour using a gas mixture (15\% $\mathrm{C}_{2} \mathrm{H}_{2}+85 \% \mathrm{~N}_{2}$ ) at a fixed total gas pressure of $7.5 \times 10^{-2} \mathrm{mbar}$ and a stable surface temperature of $645 \pm 6^{\circ} \mathrm{C}$ measured by A Chromel-Alumel thermocouple placed close to the surface. Details for rf plasma surface treatment condition of steel sample were well illustrated in previous studies [5, 11-14].

\section{Experimental procedure}

The analysis of the surface microstructure for the investigated steel samples before and after plasma surface engineering treatment were obtained using X-ray diffractometer and recorded at a Philips X' Pert $\theta-\theta$ using a $\mathrm{Cu} \mathrm{K} \alpha$ target, $\lambda=1.54184 \AA$ from (30o to $80 \mathrm{o}$ ). This study concentrates on the investigation of the average surface roughness $(\mathrm{Ra})$, wettability and gamma ray attenuation properties of the treated steel sample. At room temperature, the average surface roughness $(\mathrm{Ra})$ of the studied steel samples was optimized using a Form Talysurf 50 calibrated according to [ISO/IEC 17025:2005] requirements [15]. Also ,the water contact angle and the surface energy measurements were measured using Phoenix 300 (S.E.O Co. Ltd). The Phoenix 300 is based on advanced PC technology and Sessile Drop method. The study of gamma ray attenuation properties of the investigated steel alloys was performed experimentally at $238.63,338.28,583.19,911.2$, $968.97,1173.23,1332.49$, and $2614.51 \mathrm{keV}$ gamma ray energy lines emitted from $232 \mathrm{Th}$ and 60 Co using a $1.5^{\prime \prime} \times 1.5 " \mathrm{Na} \mathrm{I}(\mathrm{Tl})$ detector that is schematically shown in Figure(1). The obtained results were compared with the corresponding theoretical study based on the Win-X. Com computer program (Version 3.1) [16].

Table (1): Chemical composition of the studied steel alloy

\begin{tabular}{||c||c|c|c|c|c|c|c|c|c|c|c|c|}
\hline \multirow{2}{*}{ Steel } & \multicolumn{10}{c|}{ Chemical composition, wt\% } \\
\cline { 2 - 12 } & $\mathrm{C}$ & $\mathrm{Mn}$ & $\mathrm{Si}$ & $\mathrm{Cr}$ & $\mathrm{Ni}$ & $\mathrm{Mo}$ & $\mathrm{V}$ & $\mathrm{Ti}$ & $\mathrm{S}$ & $\mathrm{P}$ & $\mathrm{N}$ & $\mathrm{Fe}$ \\
\hline \hline \multirow{2}{*}{ AISI316L } & 0.02 & 1.22 & 1.94 & 16.41 & 9.89 & 2.00 & $\mathbf{0 . 1 1 5}$ & $\mathbf{0 . 2 4 6}$ & $\mathbf{0 . 0 1 0}$ & $\mathbf{0 . 0 1 0}$ & $\mathbf{0 . 0 3 0}$ & Balance \\
\hline
\end{tabular}

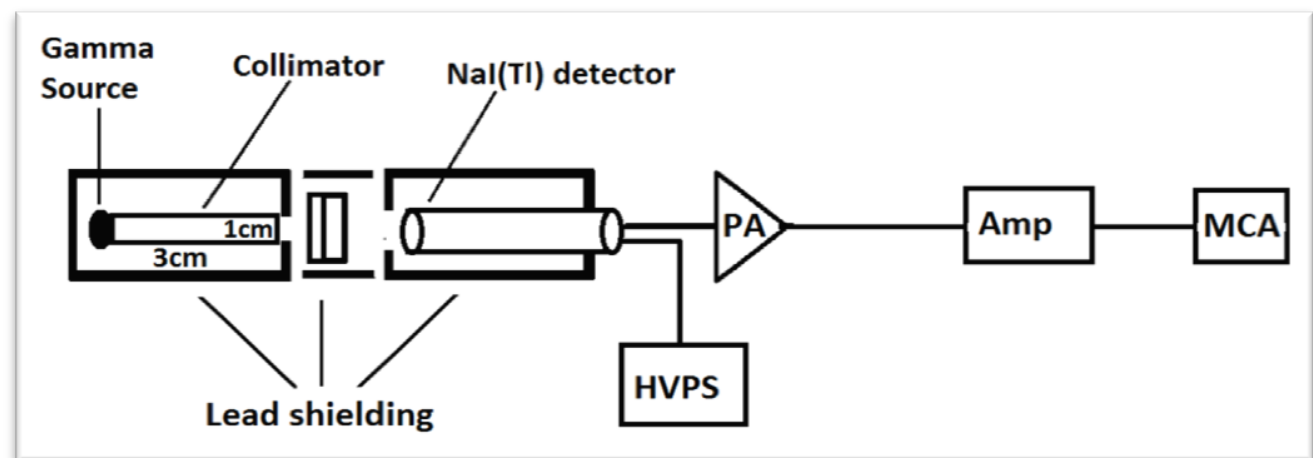

Figure (1): Experimental setup of gamma ray attenuation measurements 


\section{Results and Discussion}

$X$-ray diffraction analysis for surface microstructure

Figure (2 a, b) presents the $\mathrm{X}$ ray diffraction analysis of the studied steel samples before and after rf plasma surface engineering. Figure ( 2 a) of the untreated steel AISI316L sample shows that it is mainly austenite steel composed of $\gamma$-austenitic phase in addition to a small amount of $\alpha$-ferritic phase. Figure (2b) illustrates the effect of $\mathrm{rf}$ plasma surface engineering on the steel sample for one hour by adding small amount of $\mathrm{C} 2 \mathrm{H} 2$ to $\mathrm{N} 2$ gas at the beginning of treatment process. Such small addition of $\mathrm{C} 2 \mathrm{H} 2$ gas to the treatment process helps to overcome the native oxide layer found on the steel surface as it produces carbon species which are well known to have much more penetration ability to the steel matrix than nitrogen [17]. After that, the nitrogen species start interacting chemically and physically with the steel surface forming the carbonitrided layer [18] and producing a new phase on steel surface microstructure known by $\mathrm{\gamma N}$ to achieve thickness of nitride layer $(150 \mu \mathrm{m})$ as reported previously
[11, 13]. Moreover, the high plasma power which was stable at $500 \mathrm{~W}$ and also affects the treatment condition led to a high surface temperature $(645 \pm 6){ }^{\circ} \mathrm{C}$ [19]. Furthermore, as the steel surface temperature increased, chromium nitride is precipitated at the grain boundaries as shown in Figure (2b).

\section{Average surface roughness}

Figure (3) shows the average surface roughness of the AISI316L before and after plasma surface engineering for one hour using $\left(85 \% \quad \mathrm{~N}_{2}+15 \%\right.$ $\mathrm{C}_{2} \mathrm{H}_{2}$ ) gas mixture. As shown in Figure (3), the Ra increased after the treatment process from $(0.12 \pm$ $0.02679) \mu \mathrm{m}$ to $(0.39 \pm 0.027) \mu \mathrm{m}$ nearly by a factor of 3.25. The sharp increase in the surface roughness is also correlated with the sharp increase in steel surface temperature in addition to the effect of plasma species which cause a change in the chemical and physical properties of the top layer texture of the treated steel and lead to improving the surface tribological properties that are related to the atomic structure of the treated steel surface [5, 20-21].

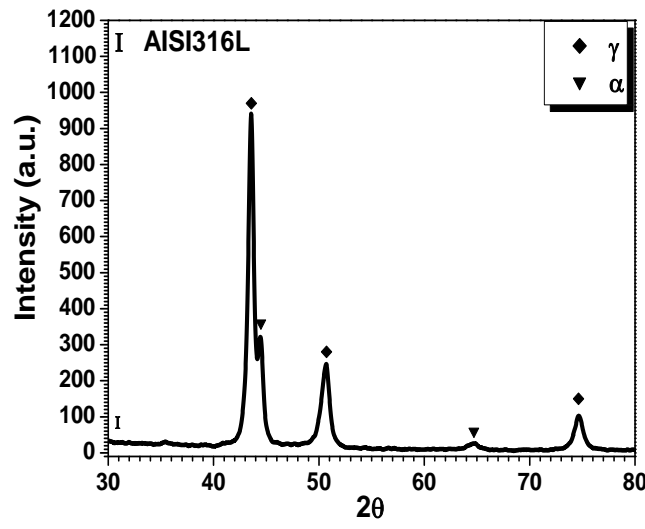

(a)

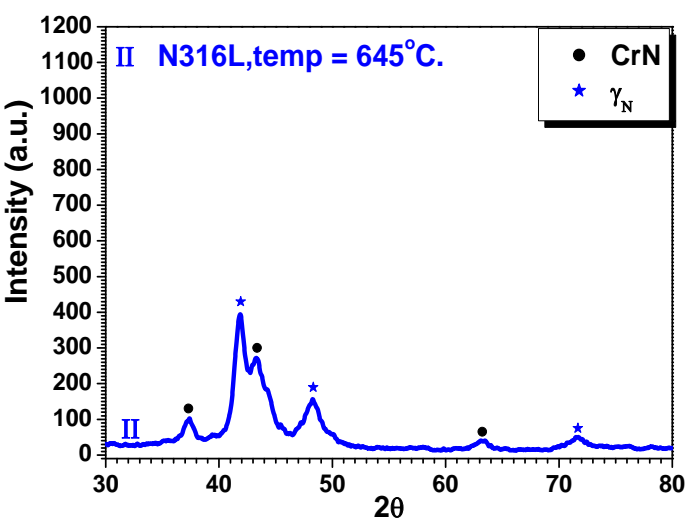

(b)

Figure (2): (a) X-ray diffraction of AISI316L steel, (b) N316L after plasma surface engineering

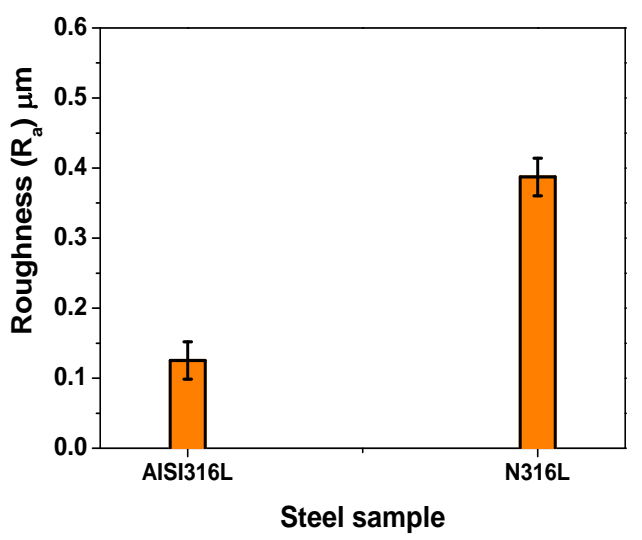

Figure (3): Average surface roughness (Ra) for steel samples 
Contact angle and surface energy

Steel wettability is defined as the interaction of water liquid with a steel surface texture. Thus, the spreading of water on the steel surface can be estimated from the contact angle measurements. The contact angle parameter can be considered an essential estimation of substrate surface quality.

Figure $(4 a, b)$ shows the Contact angle and surface energy measurements of steel samples before and after plasma surface engineering. Figure (4a) shows that the contact angle decreased from $78^{\circ}$ to $59.6^{\circ}$ as a result of that treatment which refers to a high wettability. Furthermore, Figure $(4 \mathrm{~b})$ shows that the surface energy increased from $30 \mathrm{mN} / \mathrm{m}$ for AISI316L to $50 \mathrm{mN} / \mathrm{m}$ for the N316L treated steel sample. Such a decrease in the contact angle is strongly related to the improvement in the steel surface roughness [23].

The new phases formed on the steel surface $\gamma_{\mathrm{N}}$ and $\mathrm{CrN}$ enhance the strength and the surface energy of the treated steel N316L. Therefore, the high surface energy and the wettability of the steel surface can be controlled by steel surface roughness which is considered an important characteristic of the steel surface properties.

\section{Gamma ray attenuation properties}

The linear attenuation coefficient is the most important quantity characterizing the penetration and diffusion of gamma-rays in a medium. The attenuation parameters of gamma ray at different energy lines for the investigated steel alloy before and after plasma surface engineering were obtained experimentally. As a consequence, the average values of linear attenuation coefficients $(\mu)$ of gamma rays and half value layer (HVL) were calculated and listed in Table (2). The obtained results show that there is no obvious change in the gamma rays linear attenuation coefficients $(\mu)$ and the half value layer (HVL) before and after plasma surface engineering.

Figure (5) shows a comparison between the experimental and the corresponding theoretical mass attenuation coefficients of the investigated steel alloys as a function of gamma ray energies in the energy range $238.63-2614.51 \mathrm{keV}$. As shown in Figure(3), there is a good agreement between the experimental data of mass attenuation coefficients for the two steel samples before and after plasma surface engineering and the corresponding calculated theoretical values using the Win X-Com program (version 3.1). From these data, one can conclude that there is no remarkable difference between the obtained results of the treated and untreated alloys. This result is true because the gamma ray interaction with the steel is related to $\mathrm{Z}$ number of the elements from which the steel is composed before and after plasma surface engineering process. The change in the effective atomic number is extremely small under the influence of the plasma surface engineering technique that is mainly based on light elements such as $\mathrm{H}, \mathrm{C}, \mathrm{N}$ of low $\mathrm{Z}$ number. Moreover, the penetration depth of these light elements cannot reach a large thickness $(\leq 1.0 \mathrm{~cm})$ inside the shielding steel material. Accordingly, the results of the present study reveal that although rf plasma surface treatment enhances the surface mechanical properties of the material, it has no effective change in the bulk and gamma rays attenuation properties of the investigated steel samples

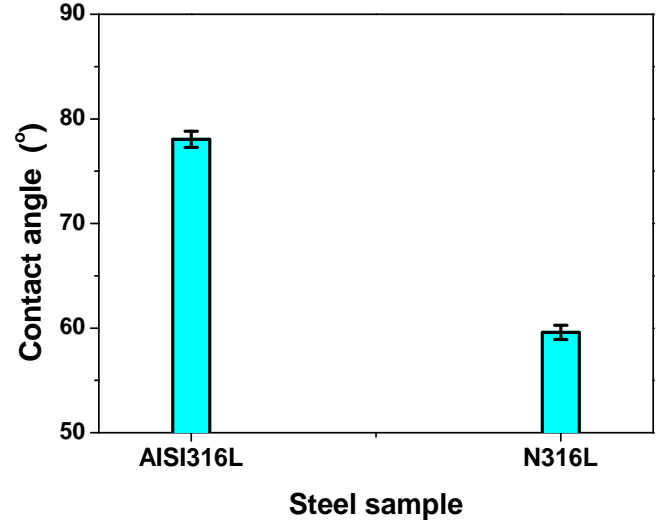

(a)

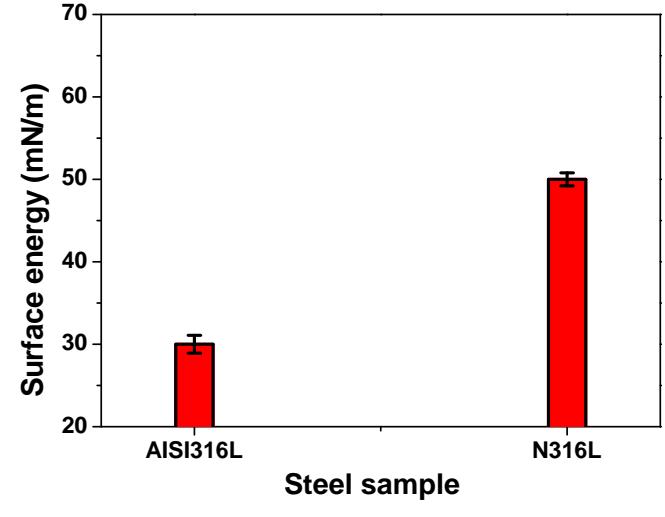

(b)

Figure(4): (a) Contact angle, (b) Surface energy measurements of steels before and after plasma surface engineering 
Table (2): Linear attenuation coefficient and half value layer for the studied alloys at different gamma ray lines

\begin{tabular}{|c|c|c|c|c|c|c|c|c|}
\hline \multicolumn{2}{|c|}{$\begin{array}{c}\text { Gama } \\
\text { Energy (kev) }\end{array}$} & 238.63 & 338.28 & 583.19 & 911.20 & 1173.23 & 1332.49 & 2614.51 \\
\hline \multirow{3}{*}{$\mu\left(\mathrm{cm}^{-1}\right)$} & AISI316L & $0.927 \pm 0.010$ & $0.795 \pm 0.022$ & $0.565 \pm 0.005$ & $0.455 \pm 0.011$ & $0.415 \pm 0.015$ & $0.401 \pm 0.001$ & $0.28 \pm 0.003$ \\
\cline { 2 - 8 } & N316L & $0.897 \pm 0.005$ & $0.782 \pm 0.005$ & $0.555 \pm 0.008$ & $0.445 \pm 0.009$ & $0.404 \pm 0.002$ & $0.385 \pm 0.005$ & $0.289 \pm 0.023$ \\
\hline \multirow{2}{*}{ HVL $(\mathrm{cm})$} & AISI316L & 0.747 & 0.872 & 1.22 & 1.52 & 1.67 & 1.72 & 2.47 \\
\cline { 2 - 8 } & N316L & 0.772 & 0.886 & 1.24 & 1.55 & 1.71 & 1.8 & 2.39 \\
\hline
\end{tabular}

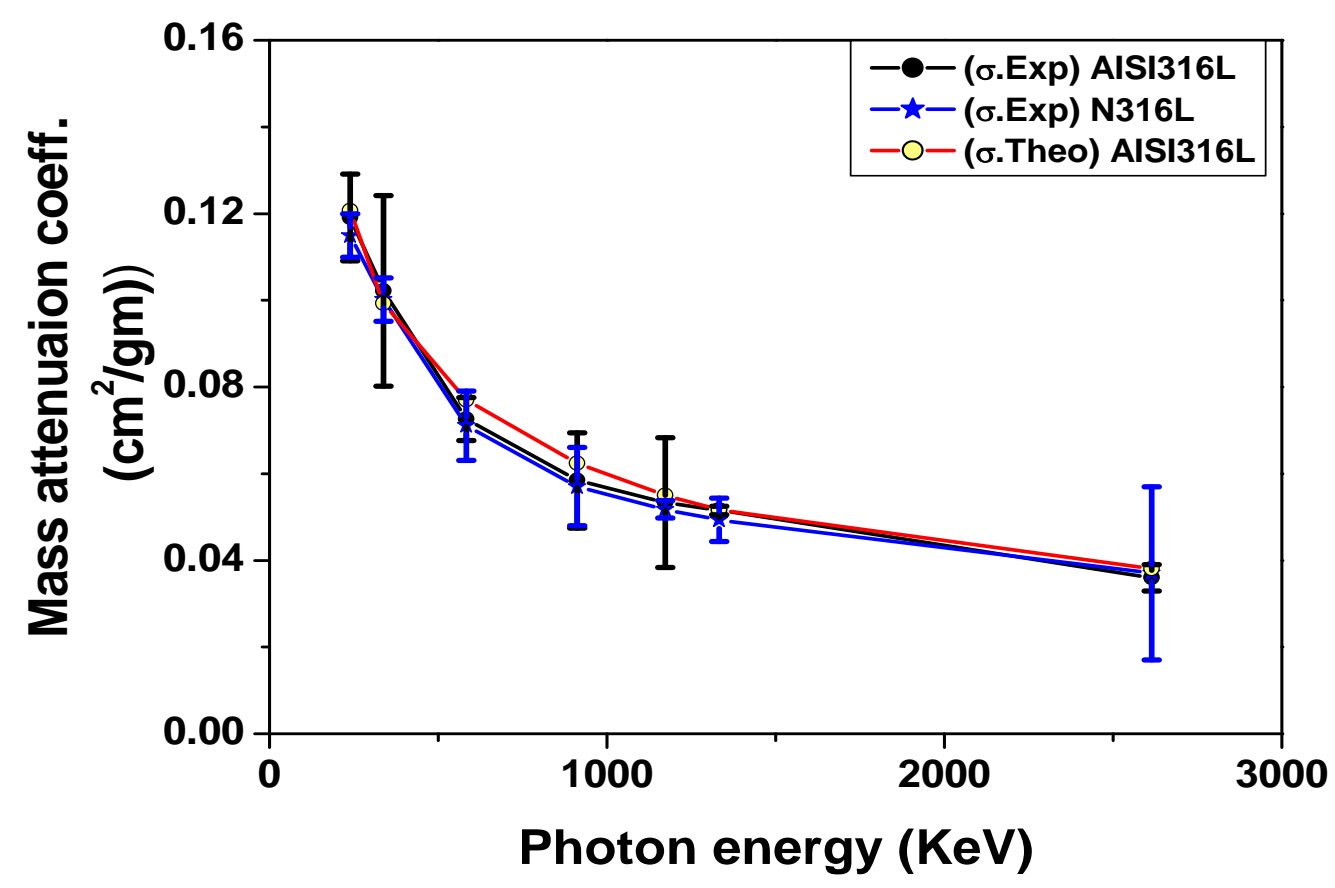

Figure (5): Mass attenuation coefficients of the investigated alloys as a function of gamma ray energies.

\section{Conclusion}

The present work is conducted to investigate the effect of plasma carbonitriding surface treatment on the average surface roughness, Contact angle, surface energy and gamma rays attenuation properties of the plasma treated and untreated steel alloys namely, AISI316L and N316L making use of the most properly used techniques and procedures. The obtained results reveal that there is a remarkable increase in the roughness and surface energy accompanied with a decrease in the contact angle i.e. reduction in the wettability under the effect of the plasma treatment. Furthermore, it is found that there is no notable change in the gamma ray attenuation properties of the investigated steel under that treatment. Therefore, the obtained results highlight the beneficial utility of plasma techniques in improving the mechanical properties of the investigated nuclear materials.

\section{References}

1- Omesh K. Chopra " Effects of Thermal Aging and Neutron Irradiation on Crack Growth Rate and Fracture Toughness of Cast Stainless Steels and Austenitic Stainless-Steel Welds", Argonne National Laboratory, Argonne, IL 60439.

2- Narveer Singh , KanwarJit Singh , Kulwant Singh and Harvinder Singh, "Comparative study of

Arab J. Nucl. Sci. \& Applic. Vol. 52, No. 2 (2019) 
lead borate and bismuth lead borate glass systems as gamma-radiation shielding materials" Nuclear Instruments and Methods in Physics Research B, ,Vol. 225, No. 3, PP. 305309, 2004.

3- F.M. El-Hossary, N.Z. Negm, S.M. Khalil, A.M. Abd Elrahman," Formation and properties of a carbonitrided layer in 304 stainless steel using different radio frequency plasma powers" , Thin Solid Films, Vol. 1, PP. 179-185, 2002

4- F. M. El-Hossary,A. M. Abd El-Rahman, M. Raaif, A. A. Seleem, M. Abo El-Kassem," Effect of rf Plasma Carbonitriding on the Biocompatibility and Mechanical Properties of AISI 321 Austenitic Stainless Steel", Advances in Materials Physics and Chemistry, Vol. 4, PP. 33-42, 2014

5- Gajendra Prasad Singh, J. Alphonsa, P.K. Barhai, P.A. Rayjada , P.M. Raole and S. Mukherjee," Effect of surface roughness on the properties of the layer formed on AISI 304 stainless steel after plasma nitriding" Surface \& Coatings Technology, Vol. 200, PP.5807-5811,2006.

6- R. N. Wenzel, "Resistance of solid surfaces to wetting by water", Industrial and engineering chemistry, Vol. 28, No. 8, PP. 988- 994, 1936.

7- D H Prajitno, A Maulana and D G Syarif," Effect of surface roughness on contact angle measurement of nanofluid on surface of stainless steel 304 by sessile drop method" 6th Asian Physics Symposium, Journal of Physics, Conference Series 739, 2016.

8- J.H. Snoeijer, B. Andreotti," A microscopic view on contact angle selection", Phys. Fluids, Vol. 20, PP. 1-11, 2008.

9- M.M. Eissa, S.U. El-kameesy, S.A. El-Fiki, S.N. Ghalia R.M. El Shazly, and Aly Saeed, "Attenuation capability of low activationmodified high manganese austenitic stainless steel for fusion reactor system", Fusion Engineering and Design, Vol. 112, PP. 130 135, 2016.

10- F. M. El-Hossary, S.U. El-kameesy, M.M. Eissa, Al-Zahraa A. Abd Elmula, Aly Saeed and Samah .A .Al-Shelkamy," Effect of plasma surface treatment on AISI 316lstainless steel for in-core applications of nuclear reactors" ICEE-4 Fourth International Conference on Energy Engineering ", Aswan ,Egypt December 26-28, 2017.

11- F.M. El-Hossary, N. Z. Negm, S.M. Khalil, A. M. Abed El-Rahman, M. Raaif, and S. Mändl,
"Effect of Annealing Temperature on Hardness, Thickness and Phase Structure of Carbonitrided 304 Stainless Steel" Applied Physics A, Vol. 99, PP. 489-495, 2010.

12- A. M. Abd El-Rahman, F. M. El-Hossary, T. Fitz, N. Z. Negm, F. Prokert, M. T. Pham, E. Richter and W. Möller, "Effect of N2 to C2H2 ratio on rf plasma surface treatment of austenitic stainless steel," Surface and Coatings Technology, Vol. 183, No. 2-3, PP. 268-274, 2004.

13- F. M. El-Hossary, "The Influence of surface microcracks and temperature gradients on the rf plasma nitriding rate," Surface and Coatings Technology, Vol. 150, No.2-3, PP. 277-281, 2002.

14- ASTM standard E384, ASTM International, West Conshohocken, PA 19428-2959, 2011.

15- L. Gerward, N. Guilbert, K. B. Jensen, and H. Leving, "WinXCom - A Program for calculating X-ray attenuation coefficients", Radiation Physics and Chemistry, Vol. 71, PP. 653-654, 2004

16- J.R.G. da Silva, Rex B. Mclellan, "Diffusion of carbon and nitrogen in B.C.C. iron", "Mat. Sci. Eng. 26, PP. 83-87, 1976.

17- F.M. El-Hossary ， N.Z. Negm, S.M. Khalil, A.M. Abed Elrahman and D.N. McIlroy " RF plasma carbonitriding of AISI 304 austenitic stainless steel", Surface and Coatings Technology, Vol. 141, PP. 194-201, 2001.

18- F.M. El-Hossary, N.Z. Negm, S.M. Khalil, M. Raaif," Surface modification of titanium by radio frequency plasma nitriding" Thin Solid Films, Vol. 497, PP. 196 - 202, 2006.

19- A.M. Abd El-Rahman, F.M. El-Hossary, F. Prokert, N.Z. Negm1, M.T. Pham and E. Richter," Corrosion performance and tribological properties of carbonitrided 304 stainless steel" Corrosion Resistance, Vol. 15, PP. 339-353, 2012.

20- Yaskiv, O.I., Pohrelyuk, I.M., Fedirko, V.M., Lee, D.B. and Tkachuk, O.V, "Formation of Oxynitrides on Titanium Alloys by Gas Diffusion Treatment", Thin Solid Films, Vol. 519, PP. 6508-6514, 2011.

21- S. H. Moita and A. L. N. Moreira "Influence of surface properties on the dynamic behavior of impacting droplets" 9th International Conference on Liquid Atomization and Spray Systems, July 2003. 